\title{
Perceived barriers to condom use among out-of-school adolescents in Kumba, southwest region of Cameroon
}

\author{
Elvis Enowbeyang Tarkang
}

HIV/AIDS Prevention Research Network, Cameroon P.O. Box 36, Commonwealth Avenue, Kumba, Southwest Region, Cameroon

\section{Email address:}

ebeyang1@yahoo.com

\section{To cite this article:}

Elvis EnowbeyangTarkang. Perceived Barriers to Condom Use among Out-of-School Adolescents in Kumba, Southwest Region of Cameroon. American Journal of Health Research. Vol. 1, No. 3, 2013, pp. 42-50. doi: 10.11648/j.ajhr.20130103.12

\begin{abstract}
Cameroon has a high concentration of out-of-school youth. Therefore research relating to out-of-school adolescents and human immunodeficiency virus/acquired immune deficiency syndrome (HIV/AIDS) is imperative. This study investigated the perceived barriers to condom use among out-of-school adolescents in Kumba, Cameroon. A crosssectional study of a probability sample of 405 adolescents aged 15-24 years was adopted. Data were analyzed using Statistical Package for Social Sciences (SPSS) software program, at the level 0.05.Most out-of-school adolescents in this study perceived certain barriers to condom use. Up to60.5\% perceived that they lacked knowledge on correct condom usage; $58.8 \%$ perceived that they would feel embarrassed to buy condoms; $54.2 \%$ would feel embarrassed to use condoms; $50.9 \%$ would feel embarrassed to ask their partners to use condoms; $70.6 \%$ believed that condom usage decreases sexual sensations, making sex less enjoyable for either partner; $70.4 \%$ believed that condom use reduces sexual urges; $66.1 \%$ respondents believed that condom use could make partner feel un-trusted; $37.8 \%$ perceived that should a condom slip off during intercourse, it could land up in the stomach of the female partner; $46.6 \%$ perceived that they would be allergic to lubricants used in condoms, and $54.8 \%$ perceived that latex condoms cause itching. Being a Christian or a male was associated with increased perceived barriers to condom use, while being a Muslim was associated with increased perceived barriers to condom negotiation. Being a female was associated with increased barrier to condom access. Perceived barriers to condom use were associated with condom non-use. Out-of-school adolescents perceived certain barriers to condom use, and consequently were not using condoms and were therefore at risk of HIV/AIDS transmission.
\end{abstract}

Keywords: Perceived Barriers to Condom Use, Out-of-School Adolescents, Condom Use, Cameroon

\section{Introduction}

One of the current challenges in the prevention and control of HIV/AIDS faced worldwide is among youths aged 15 to 24 . In fact the global population of adolescents in this age group has reached over one billion, the largest in human history, accounting for $18 \%$ of the world's population,[1] and $21.5 \%$ of Cameroon'spopulation [2]. In fact, these young men and women are the future leaders of Cameroon, thus an important age group for the growth and prosperity of the country.

Globally it is estimated that 5.4 million young people aged 15 to 24 are living with HIV/AIDS, 3.2 million of whom live in SSA [3]. In SSA, youth lack access to HIV prevention education programs, with only $8 \%$ of out-ofschool youth having access to such programs [1, 4-6]. This indicates that out-of-school youth are more at risk of contracting HIV infection due to lack of access to HIV prevention programs.

Indicators of sexual activities among young people in Cameroon have revealed that a substantial proportion of unmarried youths aged 15 to 24 years is sexually experienced, thus vulnerable to sexual risk behaviors which can expose them to sexually transmissible infections (STIs), including HIV/AIDS[7-9].

In Cameroon, HIV prevention programs have been developed to target school youths and exclude out-ofschool youths, thus increasing the risk of HIV infection among this risk age group [10, 11].

Several studies have documented the cost-effectiveness of condoms as a relatively simple intervention to prevent HIV infection [11-14]. However studies on adolescent sexuality have shown a significant increase in sexual experience at a younger age associated with inconsistent condom use $[6,11,15-17]$. Several psychosocial and cultural barriers have been associated with condom non-use 
among youth aged 15 to 24 [18-20]. Moreover, myths, misconceptions and fears that may hinder access to or use of condoms have been identified [6].

Although the overall HIV/AIDS prevalence in Cameroon is $5.3 \%$ [21], the high prevalence of $9.1 \%$ among youths age 15 to 24 [2], indicates that HIV infection is still a major problem among this at-risk age group.

To motivate youths to engage in safer sex, interventionists need insight in the utilization factors associated with condom non-use. In fact a major challenge facing HIV prevention efforts among out-of-school youths aged 15 to 24 in Cameroon, is inadequate research into perceived barriers to condom use. Identification of barriers to condom use is important for the promotion of condom use as a preventive measure against HIV/AIDS among outof-school adolescents. This study is aimed at identifying the perceived barriers to condom use among out-of-school adolescents in Kumba, Cameroon. It is hypothesized that out-of-school adolescents who perceive few barriers to condom use, would more likely use condoms during sexual intercourse to prevent HIV transmission.

\section{Data and Methods}

This study was a descriptive, cross-sectional survey, using a self-administered questionnaire to collect data. It was conducted in July 2013 in Kumba, the economic capital of the Southwest region of Cameroon, which ranks third in the HIV/AIDS prevalence.

The study population included all out-of-school adolescents in the city of Kumba, who are between the ages of 15 and 24 years and who have dropped out of school either primary or secondary school, or who have never attended at least primary school before; but they might be under apprenticeship learning a trade (hairdressing, tailoring, auto mechanic, etc).

Kumba is the administrative headquarters of Meme division, and the economic capital of the Southwest region, thus making it one of Cameroon's wealthiest urban centres, which together with the availability of economic and social amenities, industries and political institutions, has resulted in a high population density. With a total land area of 188.4 $\mathrm{Km}^{2}$, the total population of kumba, a mixture of Christians and Muslims, was estimated at 166000 inhabitants $(51.2 \%$ males and $48.8 \%$ females)[22], the majority of whom are farmers and traders[23]. Administratively, the city is divided into three local government areas.

The sample size was calculated using Epi Info 6.0 statistical software. The results of a previous study conducted in Nigeria, which showed condom use among out-of-school youth to be $29.0 \%$, was used to calculate the sample size for this study [24]. To detect a $10 \%$ difference in the rate of condom use with $95 \%$ confidence interval (CI) and $80 \%$ power, a sample of 368 was needed. With the addition of a $10 \%$ nonresponse rate, the final sample size was 405 .

A multistage sample method was applied in this study. A list of all the wards (quarters) in all the three municipalities (local government areas) of Kumba (Kumba I, Kumba II and Kumba III) was used as the sampling frame, to randomly select 15 quarters. Out of these 15 quarters, an average of 27 households per quarter was randomly selected to participate in the study. A list of all out-ofschool adolescents was made and stratified by gender. Proportional sampling according to the population distribution of Kumba was used to select the number of eligible males and females to participate in this study. Within the households, study participants were selected using systematic random sampling. Consent was obtained after the potential participants and their parents/guardians (for those below 18 years) were informed of the study's objectives. Only adolescents aged 15-24 who gave consent to participate, were included in the study. All the parents/guardians were given the opportunity to withhold or withdraw their children from the study at any time they felt like. Data for this study was part of the data set of a bigger study that investigated the knowledge of HIV/AIDS and sexual behaviors among out-of-school adolescents in Kumba in the Southwest region of Cameroon. The reliability of the questionnaire used for this study was tested using the reliability coefficient and by pretesting the questionnaire. The validity was also established by constructing items to represent the different sections of the study topic, based on literature review.

The questionnaire was designed as an adaptation from previous studies $[9,11,25,26]$, to collect data on sociodemographic characteristics, perceived barriers to condom use and condom use. A pretest of the questionnaire was done on a convenience sample of 20 out-of-school adolescents of both genders who did not take part in the study proper, for clarity and to ascertain internal consistency.

Respondents were given the self-administered questionnaires in English. Confidentiality was maintained by providing a private place for the respondents during data collection. Confidentiality was also maintained because only the researcher had access to the completed questionnaires, which were locked up. Subsequent to the acceptance of the research report, these would be destroyed. Four trained research assistants ( 2 males, 2 females) of the same age group as the participants, assisted those who could not read or write. The completed questionnaires were checked by the research assistants for errors and missing data before participants were allowed to go. Anonymously completed questionnaires were kept in a separate container from the signed informed consent forms in order to maintain anonymity.

Approval for this study was obtained from the HIV/AIDS Prevention Research Network, Cameroon (HIVPREC) research and ethics committee. Permission to conduct the study was sought from the Kumba Municipal (local government) authorities.

Data were edited, cleaned, coded, entered and analyzed using the Statistical Package for Social sciences (SPSS) 
version 20 software program. Probability $(\mathrm{P})$ values were calculated at the 0.05 level of significance. Data were summarized by means of descriptive statistics including the frequency table. Two-sided chi-square tests for association were computed to detect any associations between perceived barriers to condom use and condom use; and perceived barriers to condom use and socio-demographic characteristics of the participants.

\section{Measures}

Socio-demographic characteristics included: age which was self-reported in years, sex divided into two categories (male and female), marital status categorized into single and others, house of residence divided into two categories ( 5 rooms or more and 4 rooms or less), religion categorized into two groups (Christians and Muslims), social group affiliation divided into (yes or no) and fathers' and mothers' monthly incomes, categorized into two groups (more than 200 000XAF and 200 000XAF or less).

Perceived barriers to condom use was assessed based on the degree of agreement with the following statements: I don't know how to use condoms correctly, I would feel embarrassed to buy condoms, I would feel embarrassed to throw away condoms after use, I would feel embarrassed to ask my partner(s) to use condoms during sexual intercourse, I would feel embarrassed to use condoms, My partner(s) support condom use, My parents/guardians support condom use, I would be allergic to lubricants used in condoms, latex condoms cause itching, Should a condom slip off during sexual intercourse, it will land up in the stomach of the female partner, Condoms decrease sexual sensation, making sex less enjoyable for either partner, Condom use reduces sexual urge and condom use makes partner feel untrusted. The response options were rated on a four-point Likert scale as ' $3=$ strongly agree', ' $2=$ agree', ' $1=$ disagree' and ' $0=$ strongly disagree'. 'Strongly agree' and 'agree' were coded as the index category. The alpha reliability for the 13 -item perceived barriers to condom use scale was 0.68 .

Sexual experience was categorized into $1=$ yes and $0=$ no. Condom use during first sexual intercourse categorized into two groups $(1=$ yes, $0=$ no), condom use during last sexual encounter was categorized into $1=$ yes and $0=$ no, regularity of condom use during sexual intercourse was divided into four categories ( $1=$ always, $2=$ most of the time, $3=$ seldom and $4=$ never). These questions were asked only to respondents who were sexually active). The coefficient alpha for the 3 -item condom use scale was 0.80

\section{Results}

\subsection{Socio-Demographic Characteristics}

Of the 405 respondents in this study, 208 (51.4\%) were males and 197 (48.6\%) were females. All were between the ages of 15 and 24 years, with 375 (93.1\%) being single.
Three hundred and eighty two (94.6\%) were Christians and 353 (88.9) belonged to a social group. Majority of them, $255(64.6 \%)$ indicated that their fathers' monthly incomes were less than 200 000XAF (US\$ 13.00 a day) and 325 $(81.6 \%)$ indicated that their mothers' monthly incomes were less than 200 000XAF (US\$ 13.00 a day) (table 1). Their mean age (SD) was 18.94 (2.11).

Table1: Socio-demographic characteristics of out-of-school adolescents in Kumba, Cameroon

\begin{tabular}{|c|c|c|c|}
\hline \multicolumn{2}{|c|}{ Characteristics } & \multirow[t]{2}{*}{ Frequency } & \multirow[t]{2}{*}{ Percentage } \\
\hline$\nLeftarrow$ & Age Group (n=405) & & \\
\hline- & $15-24$ & 405 & 100.0 \\
\hline$*$ & Gender $(n=405)$ & & \\
\hline- & Male & 208 & 51.4 \\
\hline- & Female & 197 & 48.6 \\
\hline$*$ & Marital Status $(n=405)$ & & \\
\hline- & Single & 375 & 93.1 \\
\hline- & Others & 28 & 6.9 \\
\hline$*$ & $\begin{array}{l}\begin{array}{l}\text { House } \\
(n=395)\end{array}\end{array}$ of residence & & \\
\hline- & 5 rooms or more & 209 & 52.9 \\
\hline- & 4 rooms or less & 186 & 47.1 \\
\hline$*$ & Affiliation & & \\
\hline- & Christian & 382 & 94.6 \\
\hline- & Muslim & 22 & 5.4 \\
\hline$*$ & $\begin{array}{l}\text { Social group affiliation } \\
(n=397)\end{array}$ & & \\
\hline- & Yes & 353 & 88.9 \\
\hline- & No & 44 & 11.1 \\
\hline$*$ & $\begin{array}{l}\text { Father's monthly income } \\
(\mathrm{n}=395)\end{array}$ & & \\
\hline- & 200 000XAF and above & 140 & 35.4 \\
\hline- & Less than $200000 \mathrm{XAF}$ & 255 & 64.6 \\
\hline$*$ & $\begin{array}{l}\text { Mother's monthly income } \\
(\mathrm{n}=399)\end{array}$ & & \\
\hline- & 200 000XAF and above & 74 & 18.5 \\
\hline- & Less than $200000 \mathrm{XAF}$ & 325 & 81.5 \\
\hline
\end{tabular}

\subsection{Perceived Barriers to Condom Use}

As the data reveal (table 2), Most out-of-school adolescents perceived certain barriers in accessing and using condoms. Of the respondents, 245 (60.5\%) perceived that they lacked knowledge on correct condom usage; 238 (58.8\%) perceived that they would feel embarrassed to buy condoms; 219 (54.2\%) would feel embarrassed to use condoms; and 206 (50.9\%) would feel embarrassed to ask their partners to use condoms during sex.

Out-of-school adolescents in Kumba might also hold different views about condoms, influencing their perceptions regarding condom usage. In the current study, $286(70.6 \%)$ perceived that condom usage decreases sexual sensations, making sex less enjoyable for either partner; $285(70.4 \%)$ perceived that condom use reduces sexual urges; $268(66.1 \%)$ respondents believed that condom use could make partner feel un-trusted. 
Table 2: Perceived barriers to condom use among out-of-school adolescents in Kumba, Cameroon

\begin{tabular}{|c|c|c|c|}
\hline \multicolumn{2}{|c|}{ Perceived barriers } & \multirow{2}{*}{ Frequency } & \multirow[t]{2}{*}{ Percentage } \\
\hline$\%$ & $\begin{array}{l}\text { I don't know how to use } \\
\text { condoms correctly }(n=405)\end{array}$ & & \\
\hline- & Agree & 245 & 60.5 \\
\hline- & Disagree & 160 & 39.5 \\
\hline$*$ & $\begin{array}{l}\text { I would feel embarrassed to } \\
\text { buy condoms }(n=405)\end{array}$ & & \\
\hline- & Agree & 238 & 58.8 \\
\hline- & Disagree & 167 & 41.2 \\
\hline$*$ & $\begin{array}{l}\text { I would feel embarrassed to } \\
\text { throw away condoms after } \\
\text { usage }(n=404)\end{array}$ & & \\
\hline- & Agree & 188 & 46.5 \\
\hline- & Disagree & 216 & 53.5 \\
\hline$*$ & $\begin{array}{l}\text { I would feel embarrassed to } \\
\text { ask my partner(s) to use } \\
\text { condoms during sex }(n=405)\end{array}$ & & \\
\hline- & Agree & 206 & 50.9 \\
\hline- & Disagree & 199 & 49.1 \\
\hline$*$ & $\begin{array}{l}\text { I would feel embarrassed to } \\
\text { use condoms during sexual } \\
\text { intercourse }(n=404)\end{array}$ & & \\
\hline- & Agree & 219 & 54.2 \\
\hline- & Disagree & 185 & 45.8 \\
\hline$*$ & $\begin{array}{l}\text { My partner(s) support } \\
\text { condom use }(n=405)\end{array}$ & & \\
\hline- & Agree & 249 & 61.5 \\
\hline- & Disagree & 156 & 38.5 \\
\hline$*$ & $\begin{array}{l}\text { My parents/guardians } \\
\text { support condom use }(n=405)\end{array}$ & & \\
\hline- & Agree & 274 & 67.6 \\
\hline- & Disagree & 131 & 32.4 \\
\hline$*$ & $\begin{array}{l}\text { I would be allergic to } \\
\text { lubricants used in condoms } \\
(n=405)\end{array}$ & & \\
\hline- & Agree & 189 & 46.6 \\
\hline- & Disagree & 216 & 53.4 \\
\hline 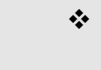 & $\begin{array}{l}\text { Latex condoms cause itching } \\
(n=405)\end{array}$ & & \\
\hline- & Agree & 222 & 54.8 \\
\hline- & Disagree & 183 & 45.2 \\
\hline$*$ & $\begin{array}{l}\text { Should a condom slip off } \\
\text { during sexual intercourse, it } \\
\text { will land up in the stomach } \\
\text { of the female partner }(n=405)\end{array}$ & & \\
\hline- & Agree & 153 & 37.8 \\
\hline- & Disagree & 252 & 62.2 \\
\hline$\nLeftarrow$ & $\begin{array}{l}\text { Condoms decrease sexual } \\
\text { sensation, making sex less } \\
\text { enjoyable for either partner } \\
(\mathrm{n}=\mathbf{4 0 5})\end{array}$ & & \\
\hline- & Agree & 286 & 70.6 \\
\hline- & Disagree & 119 & 29.4 \\
\hline$*$ & $\begin{array}{l}\text { Condom use reduces sexual } \\
\text { urge }(n=405)\end{array}$ & & \\
\hline- & Agree & 268 & 66.1 \\
\hline- & Disagree & 137 & 33.9 \\
\hline$*$ & $\begin{array}{l}\text { Condom use makes partner } \\
\text { feel untrusted }(n=405)\end{array}$ & & \\
\hline- & Agree & 285 & 70.4 \\
\hline- & Disagree & 120 & 29.6 \\
\hline
\end{tabular}

Some respondents, $153(37.8 \%)$ perceived that should a condom slip off during intercourse, it could land up in the stomach of the female partner; $189(46.6 \%)$ perceived that they wouldbe allergic to lubricants used in condoms, and $222(54.8 \%)$ perceived that latex condoms cause itching.

\subsection{Condom Use during Sexual Intercourse}

With regard to sexual experience, the majority, 225 $(55.6 \%)$ reported having experienced sex. Only few sexually experienced out-of-school adolescents in this study, $67(29.8 \%)$ reported having used condoms during their first sexual encounters. In the same vein, only 110 (48.9\%) reported having used condoms during their most recent sexual encounters, while consistent condom use among the sexually active out-of-school adolescents was very low, 42 $(18.7 \%)$ (table 3).

Table 3: Sexual experience and condom use among sexually experienced out-of-school adolescents in Kumba

\begin{tabular}{|c|c|c|c|}
\hline \multicolumn{2}{|c|}{ Sexual behaviors } & Frequency & Percentage \\
\hline$\%$ & 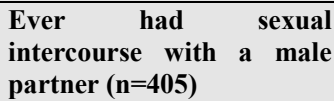 & & \\
\hline - & Yes & 225 & 55.6 \\
\hline - & No & 180 & 44.4 \\
\hline$*$ & $\begin{array}{l}\text { Condom use during first } \\
\text { sexual encounter }(n=225)\end{array}$ & & \\
\hline - & Yes & 67 & 29.8 \\
\hline - & No & 158 & 70.2 \\
\hline$*$ & $\begin{array}{l}\text { Condom use during last } \\
\text { sexual encounter }(n=225)\end{array}$ & & \\
\hline - & Yes & 110 & 48.9 \\
\hline- & No & 115 & 51.1 \\
\hline$*$ & $\begin{array}{l}\text { Regularity of condom use } \\
\text { during sexual intercourse } \\
(n=225)\end{array}$ & & \\
\hline - & Always & 42 & 18.7 \\
\hline- & Most of the time & 74 & 32.9 \\
\hline- & Seldom & 39 & 17.3 \\
\hline- & Never & 70 & 31.1 \\
\hline
\end{tabular}

\subsection{Associations between Perceived Barriers to Condom Use and Gender}

As revealed in table 4, more males than females perceived the following barriers:

- That condom decreases sexual sensation, making sex less enjoyable for either partner

- That condom use makes partner feel untrusted

- That they would feel embarrassed to use condoms

- That they would feel embarrassed to ask their partners to use condoms

- That they would feel embarrassed to throw away condoms after use

On the other hand, more females than males perceived the following barriers to condom use:

- That they would feel embarrassed to buy condoms

- That their parents/guardians would not support condom use

- That they don't know how to correctly use condoms 
Table 4: Associations between perceived barriers to condom use and gender

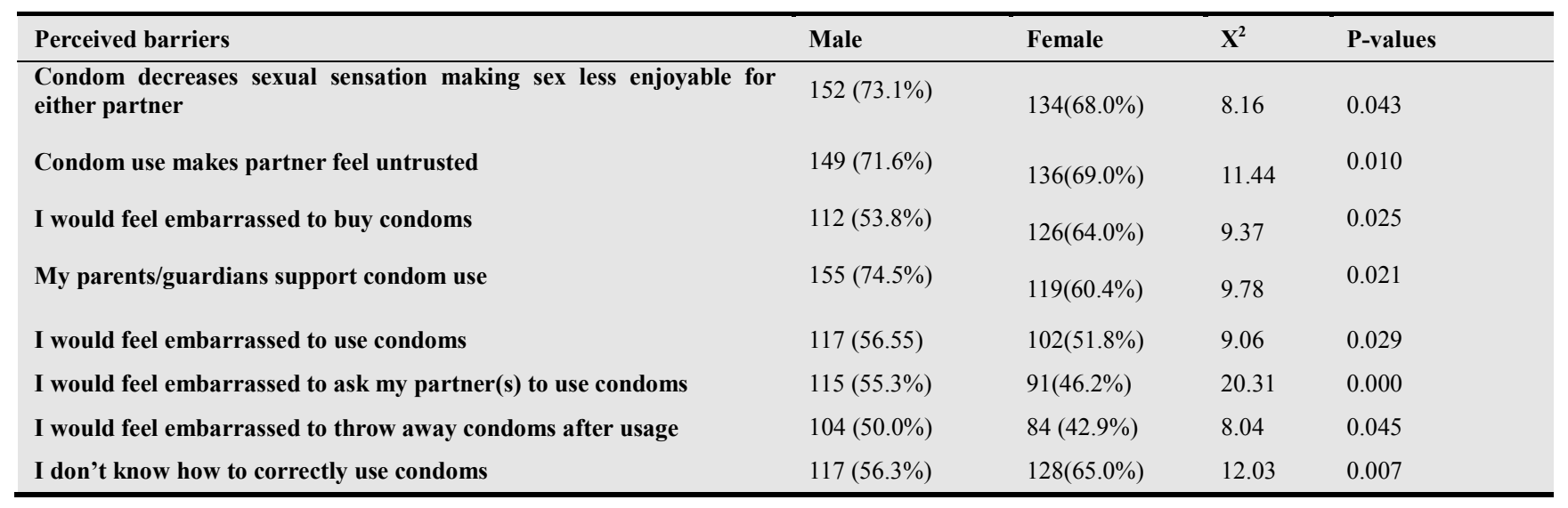

\subsection{Associations between Perceived Barriers to Condom Use and Religion}

As could be seen in table 5, more Christians than Muslims perceived the following barriers:

- That condom decreases sexual sensation making sex less enjoyable for either partner

- That they don't know how to correctly use condoms On the other hand, more Muslims than Christians perceived that they would feel embarrassed to ask their partners to use condoms during sexual intercourse.

Table 5: Associations between perceived barriers to condom use and religion

\begin{tabular}{|c|c|c|c|c|}
\hline Perceived barriers & Christian & Muslim & $\mathrm{X}^{2}$ & P-values \\
\hline $\begin{array}{l}\text { Condom decreases sexual sensation making sex less enjoyable for } \\
\text { either partner }\end{array}$ & $273(71.5 \%)$ & $12(54.5 \%)$ & 22.14 & 0.036 \\
\hline I feel embarrassed to ask my partner(s) to use condoms & $189(49.5 \%)$ & $16(72.7 \%)$ & 22.35 & 0.034 \\
\hline I don't know how to correctly use condoms & $235(61.5 \%)$ & $9(40.9 \%)$ & 21.50 & 0.044 \\
\hline
\end{tabular}

\subsection{Associations between Perceived Barriers to Condom Use and Condom Use}

Table 6 reveals the following associations between perceived barriers to condom use and condom use:

Respondents who did not perceive the following barriers to condom use, used condoms more than those who perceived the barriers:

- That condom decreases sexual sensation making sex less enjoyable for either partner

- $\quad$ That condom use makes partner feel untrusted
- That their parents/guardians don't support condom use

- That their partners don't support condom use

- That they feel embarrassed to ask their partners to use condoms

- That they feel embarrassed to throw away condoms after use

- That they don't know how to correctly use condoms

- That they feel embarrassed to use condoms

Table 6: Associations between perceived barriers to condom use and condom use

\begin{tabular}{|c|c|c|c|c|}
\hline \multirow[b]{2}{*}{ Perceived barriers } & \multicolumn{4}{|c|}{ Condom use at first sex } \\
\hline & Agree & Disagree & $\mathbf{X}^{2}$ & P-values \\
\hline $\begin{array}{l}\text { Condom decreases sexual sensation making sex less enjoyable for } \\
\text { either partner }\end{array}$ & $50(29.4 \%)$ & $21(35.6 \%)$ & 14.24 & 0.027 \\
\hline Condom use makes partner feel untrusted & $47(29.7 \%)$ & $24(33.8 \%)$ & 18.38 & 0.005 \\
\hline My partner(s) support condom use & $55(36.2 \%)$ & $16(20.8 \%)$ & 20.80 & 0.002 \\
\hline My parents/guardians support condom use & $62(36.3 \%)$ & $9(15.5 \%)$ & 21.53 & 0.001 \\
\hline I feel embarrassed to use condoms & $30(30.3 \%)$ & $30(25.2 \%)$ & 26.64 & 0.000 \\
\hline I feel embarrassed to ask my partner(s) to use condoms & $31(30.1 \%)$ & $40(31.7 \%)$ & 18.46 & 0.005 \\
\hline I feel embarrassed to throw away condoms after usage & $25(26.6 \%)$ & $46(34.1 \%)$ & 15.93 & 0.014 \\
\hline I don't know how to correctly use condoms & $38(28.8 \%)$ & $33(34.0 \%)$ & 14.40 & 0.025 \\
\hline
\end{tabular}




\begin{tabular}{|c|c|c|c|c|}
\hline \multirow[b]{2}{*}{ My parents/guardians support condom use } & \multicolumn{4}{|c|}{ Condom use at last sex } \\
\hline & $99(57.9 \%)$ & $17(28.3 \%)$ & 26.42 & 0.000 \\
\hline My partner(s) support condom use & $90(59.2 \%)$ & $26(32.9 \%)$ & 27.58 & 0.000 \\
\hline I feel embarrassed to use condoms & $45(45.0 \%)$ & $70(53.8 \%)$ & 29.89 & 0.000 \\
\hline I feel embarrassed to ask my partner(s) to use condoms & $43(41.3 \%)$ & $73(57.7 \%)$ & 20.43 & 0.002 \\
\hline \multirow[t]{2}{*}{ I don't know how to correctly use condoms } & $60(45.5 \%)$ & $56(56.7 \%)$ & 12.73 & 0.047 \\
\hline & \multicolumn{4}{|c|}{ Consistent condom use } \\
\hline Condom use makes partner feel untrusted & $31(18.8 \%)$ & $23(31.9 \%)$ & 24.12 & 0.020 \\
\hline My parents/guardians support condom use & $49(27.8 \%)$ & $5(8.2 \%)$ & 32.47 & 0.001 \\
\hline My partner(s) support condom use & $43(27.4 \%)$ & $11(13.8 \%)$ & 35.72 & 0.000 \\
\hline I feel embarrassed to use condoms & $23(22.1 \%)$ & $31(23.5 \%)$ & 43.52 & 0.000 \\
\hline $\begin{array}{l}\text { I feel embarrassed to ask my partner(s) to use condoms during sexual } \\
\text { intercourse }\end{array}$ & $19(17.9 \%)$ & $35(26.7 \%)$ & 20.43 & 0.002 \\
\hline
\end{tabular}

\section{Discussion}

This study investigated the perceived barriers to condom use among out-of-school adolescents in Kumba, Cameroon.

In agreement with other studies, [27, 28] out-of-school adolescents in this study perceived that latex condoms cause itching, and that their penis or vagina would be allergic to lubricants with which some condoms are treated

These side effects could act as barriers deterring out-ofschool adolescents from using condoms correctly and consistently during sexual intercourse to prevent sexual transmission of HIV/AIDS, even when they perceive themselves at risk of the disease. For people who may have an allergic skin reaction to latex, male condoms made of polyurethane are available [29].

Some people also associate condom with promiscuity, probably because of their extensive advertisement in AIDS educational programs in the media, especially on the television. People who buy condoms are often stigmatized [30]. Youths may therefore abstain from using condoms during sexual intercourse with both casual and steady partners. In this study, out-of-school adolescents perceived that they would feel embarrassed to buy and use condoms. There should be no embarrassment in using or buying condoms. A condom can be bought or used at any age [31].

One other major barrier to condom use among participants in this study which is in agreement with other reports among urban youth in Mozambique and Kenya was the perception that they did not have to use condoms in a steady relationship built on love and trust, which provide a sense of immunity to infection $[32,33]$. Using a condom should not make partner feel untrusted. Insisting on condom use suggests that one knows how to take care of oneself. It also shows that one is aware of the benefits of condom use during sex.

In accordance with other reports in Mexico, lack of knowledge of condom use was a barrier among out-ofschool adolescents in this study [34]; in Nigeria, truck drivers believe condom use reduces their sexual satisfaction and hinder their sexual interest [35], while men in Kenya perceive condom as unpleasant and hard to use [36].

Using a condom does not decrease sensation or make sex less enjoyable. It can cause some men to take longer before they ejaculate which could be good for both partners. There are many different sizes, shapes, textures and flavors of condoms; partners should fine the combination that suits them best.

In agreement with the report from Nigeria, [37] out-ofschool adolescents in this study perceived that condom usage was unsafe, and they believed that condoms could break away and go into the stomach of the female partner and cause difficulty in breathing. Condoms do not break or slip off during sex, unless they are being used incorrectly. To avoid a condom breaking, one needs to put it on carefully, ensuring there is no air bubble at the end and be careful of sharp nails, jewelry or teeth [29].

Religious beliefs significantly shape individual's perceived barriers to condom use [38]. In this study, being a Christian was associated with increased perceived barriers to condom use as compared with Muslims. This finding is in agreement with findings from other studies [39, 40].Since its very inception, the Roman Catholic Church has forbidden the application of contraceptive measures because it considers that such interference is a transgression of divine law and a sin against nature. The use of contraceptive is prohibited whatever the circumstances. This also applies to the condom even when one intends to use it, not to prevent pregnancy, but to avoid fatal infections such as HIV/AIDS. For instance, the use of a condom within the marital relationship even when one of the spouses is HIV positive is considered sinful [41].

This interdict has had the direct consequence with regard to the implementation of AIDS prevention programs among Christians, especially Catholics in the developing countries.The protestant churches also emphasize birth control basing their views on their puritan tradition and 
responsibility founded on a Christian social ethics.

The Islamic law states that children are the gift of Allah. Some Muslims believe that they must have many children and they may oppose condom use. However, according to Islamic faith, children have right to education and future security, which entails that their number may have to be limited and thus that birth control is licit. Condom use is prohibited neither for prevention of unintended pregnancy nor for HIV prevention [41]. Moreover, Muslims must also abide by the Islamic moral code that forbids adultery, premarital sex and homosexuality to reduce the risk of HIV infection. Among Muslims, gender roles, access to contraceptives and traditional family values have more effect on condom than theological and religious barriers. This might be the reason why more Muslims than Christians in this study perceived that they would feel embarrassed to ask their partners to use condoms.

In this study, female respondents were more likely than males to perceive barriers to condom access and negotiation. This is probably linked to the fact that this study refers to male condoms; and male respondents are generally mobile and have more access to information on condoms and the ability to buy condoms, and parental support for condom use. In addition gender disparities in condom negotiation skills may explain the discrepancies of perceived barriers between males and females [18]. Women reported that the relationship with their partners had been difficult because of the absence of dialogue about sexual matters and men always had the final word. Despite being informed about HIV/AIDS, women did not use preventive measures in their steady relationships because they did not wield decision-making powers [42].

In various communities, women as well as men involved in a steady on-going sexual relationship admitted avoidance of condom use due to fear of being suspected of infidelity that could lead to separation of the couple. The condom negotiation scenario may be very risky for a woman when she is charged with infidelity. The violent behavior of a male partner within the relationship predicts a more coercive response to a woman's condom negotiation with the allegation of infidelity on the part of the woman. Many women at high risk of HIV infection face resistance and in some cases violence as a response to their request that a condom be used. Evidently, this scenario suggests that domestic violence acts as a barrier to condom use during sexual intercourse.

Being a woman, having less schooling, being jobless and having low per capita family income are factors related to condom non-use among young people having sex with steady partners. Male adolescents in this study perceived barriers to condom use than females. Men's emotional fulfillment with attainment of satisfaction through direct penile-vaginal contact and ejaculation during natural intercourse is an obstacle to condom use. Some men perceive prolonged sexual intercourse without a condom as a sexual prowess in the domain of masculinity and seek to preserve this manly skill by avoiding condom use [43].

\section{Conclusion}

All these perceived barriers to condom use could deter out-of-school adolescents in Kumba, Cameroon from using condoms consistently during sexual intercourse to prevent transmission of HIV. These barriers might well be contributory to the fact that knowledge and perceptions do not always result in corresponding and expected behavior. In this study, only $18.7 \%$ of the sexually experienced outof-school adolescents were using condoms consistently.

The hypothesis that perceived barriers to condom use among out-of-school adolescents is associated with condom non-use, is accepted at the level 0.05 .

It is recommended that the institution which carried out this study, (HIVPREC), should cooperate with national health agencies to address issues relating to these agencies. Sexuality education programs for out-of-school adolescents should also aim at "normalizing" both HIV/AIDS and condom use (teenage sexual activities). All these actions call for cooperation among multiple organizations such as parents, the community and national health agencies involved in adolescent's sexuality education programs.

Campaigners promoting condoms should consider these improper perceptions and orientation affecting many outof-school adolescents when propagating its use in the context of HIV/AIDS prevention programs. These barriers to condom use must be highlighted to make out-of-school adolescents to overcome them. Education will help group at risk of HIV infection to understand the necessity of using this device to avoid contracting STIs including HIV/AIDS.

\section{Limitation}

The study must be interpreted in light of its limitations. First as a cross-sectional study, it is not able to draw conclusions about causality of any of its identified associations. Second, given that this study was conducted in one location in Cameroon, it may not be applicable to other settings.

\section{Acknowledgements}

Mr Dadah Emana, who has been the research assistant working with me all this while, without whom this study would not have been possible.

\section{Competing Interests}

The author declares that he has no competing interests.

\section{References}

[1] UNFPA, Youths and HIV/AIDS Fact Sheet: State of the world population, 2009.2 From: http://www.unfpa.org/swp/2009/presskit/factsheets/facts_youth. $\mathrm{htm}$

[2] UNFPA, Country profiles for population and reproductive 
health: policy developments and indicators, Cameroon,pp. 26-27, $2005 . \quad$ From: http://www.unfpa.org/upload/lib_pub_file/524_filename_Co untry_Profiles_2005.pdf

[3] International Youth Foundation. From:http://www.iyfnet.org/document.cfm/748

[4] N. Imanguli, Youth and the global HIV/AIDS pandemic: Advocates for youth, 2008 . From:http://www.advocatesforyouth.org/storage/advfy/docu ments/fsglobalhiv.pdf

[5] UNAIDS, and WHO,Epidemiological fact sheet on HIV and AIDS, 2009.

From:http://apps.who.int/globalatlas/predefinedReports/EFS2009/full/EFS2009_HT.pdf

[6] UNAIDS, and WHO, AIDS epidemic updates. Geneva: UNAIDS, 2010. From:http://www.who.int/whosis/en/

[7] J. L. Arcand, and E. D. Wouabe, Teacher training and HIV/AIDS prevention in West Africa: Regression discontinuity design evidence from the Cameroon, Health Economics, vol. 19, pp. 36-24, 2010.

[8] E. J. Kongnyuy,V. Soskolne, and B. Adler, Hormonal contraception, sexual behaviour and HIV prevalence among women in Cameroon.,BMC Women's Health, vol. 8(19), pp. $1-6,2008$.

[9] E. E. Tarkang, Age at sexual debut and associated factors among high school female learners in Limbe urban area of Cameroon, GARJSS,vol. 2(7), pp. 163-168, 2013 b.

[10] E. C. Haddison, G.Ngeufack-Tsague, M.Noubom, W.Mbatcham, P. M.Ndumbe, and X.Mbopi-Keou, Voluntary counseling and testing for HIV among high school students in theTiko Health District, Cameroon, Pan Afr Med J,vol. 13:18, 2012.

[11] E. E. Tarkang, Factors associated with consistent condom use among senior secondary school female learners in Mbonge subdivision of rural Cameroon, JAHR,vol. 5(6),pp. 214-223, 2013a.

[12] W. Jr. Cates, The NIH condom report: the glass is $90 \%$ full, Family Planning Perspectives,vol. 33(5), pp. 231-233, 2001.

[13] K. Holmes, R. Levine, and M. Weaver, Effectiveness of condoms in preventing sexually transmitted infections, Bulletin of the World Health Organization. Geneva, June 2004.

[14] M. Rwenge, Sexual risk behaviours among young people in Bamenda, Cameroon, International Family Planning Perspectives, vol. 26(3), pp. 118-123 \& 130, 2000.

[15] H. Alemu, D. H. Mariam,K. A. Belay,and G. Davey, Factors predisposing out-of-school youths to HIV/AIDS-related risky sexual behaviour in northwest Ethiopia, Journal of Health, Population and Nutrition, vol. 25(3), pp. 344-350, 2007.

[16] L. A. Lema, R. S.Katapa,and S. A. Musa, Knowledge on HIV/AIDS and sexual behaviour among youths in Kibaha District, Tanzania, Tanzania Journal of Health Research, vol. 10(2), pp. 79-83, 2008

[17] R. Van Rossem, and D.Meekers, An evaluation of the effectiveness of targeted social marketing to promote adolescent and young adult reproductive health in Cameroon, AIDS Education and Prevention, vol. 12, pp. 383-404, 2000.

[18] B. Njau, S. Mtweve, L. Barongo, R. Manongi, J. Chugulu, M. Msuya, S. Mwampeta, B. Kiwale, J. Lekule, and R. Jalipa, The influence of peers and other significant persons on sexuality and condom use among young adults in northern Tanzania, African Journal of AIDS Research, vol. 5(3),pp. 33-40, 2006

[19] S. M. Noar, Behavioral interventions to reduce HIV-related sexual risk behaviour: Review and synthesis of metaanalytic evidence, AIDS and Behavior, vol. 12(3), pp. 335$353,2008$.

[20] N. Prata, L. Morris, E.Mazive, F.Vahidnia, M.Stehr, Relationship between HIV risk perception and condom use: evidence from a population-based survey in Mozambique, International Family Planning Perspectives, vol. 32(4), pp. 192-200, 2006.

[21] UNAIDS, Report on the global AIDS epidemic. Geneva, Switzerland, UNAIDS, 2010

[22] Bureau Central des Recensementset des etudes de Population (BCREP), Livre "Rapport de Presentation, Cameroon, 2010.

[23] Kumba Urban Council (KUC), Kumba Urban Council Statistical Year Book, Buea, The National Printing Press, 2000.

[24] A. O. Adebiyi, M. C.Asuzu, Condom use amongst out-ofschool youths in a local government area in Nigeria, African Health Sciences, vol. 9(2), pp. 92-97, 2009.

[25] E. J. Essien, E.Monjok, H. Chen,S. Abughosh, E. Ekong, R. J. Peters, L. Jr. Holmes, M. M. Holstad, and O. Mgbere, Correlates of HIV knowledge and sexual risk behaviors among female military personnel. AIDS Behav, vol. 14(6),pp. 1401-14, 2010.

[26] O. Oladepo, and M. M. Fayemi, Perceptions about sexual abstinence and knowledge of HIV/AIDS prevention among in school adolescents in a western Nigerian city,BMC Public Health, vol. 11: 304, 2011.

[27] R. A. Crosby,C. A. Graham, W. L.Yarber, S. A. Sanders, If condom fits, wear it: A qualitative study of young AfricanAmerican men, Sex Trans Infect, vol. 80, pp. 306-309, 2004.

[28] R. A. Crosby,W. L. Yarber, S. A. Sanders, andC. A. Graham, Condom discomfort and associated problems with their use among university students, J Am Coll Health, vol. 54, pp. 143-147, 2005.

[29] L. Hirsch, About birth control: condoms. Nemours Foundation, 2007.2 From: http://www.kidshealth.org/parent/growth/sexual_health/cond oms.html

[30] A. Kulcrycki, The socio-cultural context of condom use within marriage in rural Lebanon, Stud FamPlann, vol 35, pp. 246-260, 2004.

[31] P. Tina, Condoms: know the facts, 2008. From: http://www.nhs.uk/livewell/teengirls/pages/condoms.aspx (accessed 14/02/2009).

[32] S. Manuel, Obstacles to condom use among secondary 
school students in Maputo city, Mozambique, Cult Health Sex, vol. 7, pp. 293-302, 2005.

[33] H. A. Voeton, O. B. Egesah, C. M.Varkevisser, and J. D. Habbema, Female sex workers and unsafe sex in urban and rural Nyanza, Kenya: Regular partners may contribute more to HIV transmission than clients, Trop MedInt Health, vol. 12,pp. 174-182, 2007.

[34] J. Bucardo, S. J.Semple, M. Fraga-Vallejo, W. Davila, and T. L. Patterson, A qualitative exploration of female sex workers in Tijuana, Mexico, Arch Sex Behav, vol. 33(4), pp. 343-351, 2004.

[35] A. M. Sunmola, Sexual practices, barriers to condom use and its consistent use among long distance truck drivers in Nigeria, AIDS Care, vol. 17,pp. 208-221, 2005.

[36] S. Thomsen,M. Stalker, and C.Toroitich-Ruto, Fifty ways to leave your rubber. How men in Mombasa rationalise unsafe sex, Sex Transm Infect, vol. 80, pp. 430-434, 2004.

[37] U. Amazigo, N. Silva, J. Kaufman, and D.Obikeze, Sexual activity and contraceptive knowledge and use among inschool adolescents in Nigeria,International Family Planning Perspectives, vol. 23(1), pp. 28-33, 1997.
[38] A. Ragnarsson, H. E.Onya, andL. E. Aaro, A young person understands HIV: a qualitative study among school students in Mankweng, South Africa, Scand J Public Health, vol. 37(2),pp. 101-106, 2009.

[39] P. B. Gray, HIV and Islam: Is HIV prevalence lower among Muslims? Social Science and Medicine, vol. 58, pp. 17511756, 2004.

[40] E. Lagarde, C.Enel, K.Seck, A.Gueye-Ndiaye, J. P.Piau, G.Pison, and S.Mboup, Religion and protective behaviour towards AIDS in rural Senegal, AIDS, vol. 14, pp. 20272033, 2000 .

[41] J. G. Schenker, and V.Rabenon, Contraception: Traditional and religious attitudes, Eur J Obstet Gynecol Reprod Biol, vol. 49 , pp. 15-18, 1993.

[42] E. M. Hebling, and I. R.Guimaraes, Women and AIDS: Gender relations and condom use with steady partners, Cad Saude Publica, vol. 20, pp.1211-1218, 2004.

[43] I. Khan,N. Hudson-Rodd, and S.Saggers, Safer sex or pleasurable sex? Rethinking condom use in the AIDS era, Sex Health, vol. 1, pp. 217-225, 2004. 